\title{
Changes of caprine (Capra hircus) blood during prolong storage for transfusion
}

\author{
M. N. Jahan, M. R. Munif, M. Sohag, M. M. Alam, M. R. Alam* \\ Department of Surgery and Obstetrics, Faculty of Veterinary Science, Bangladesh Agricultural \\ University, Mymensingh-2202, Bangladesh
}

\begin{abstract}
Background: This experiment was performed to investigate the effects of acid citrate dextrose (ACD) and citrate phosphate dextrose adenine-1 (CPDA-1) on the keeping qualities of various haematological and biochemical parameters of caprine blood during long time preservation and storage for transfusion.
\end{abstract}

Methods: Sixteen healthy goats were selected and divided into 2 equal groups $(\mathrm{A}, \mathrm{n}=8$ and $\mathrm{B}$, $\mathrm{n}=8)$. Fifty $\mathrm{ml}$ of blood was collected from each goat and preserved with ACD for group A $(n=8)$ and CPDA- 1 for group $B(n=8)$. All the samples were stored at $4^{\circ} \mathrm{C}$ in refrigerator for 28 days. The recorded blood parameters were total erythrocyte count (TEC), total leucocyte count (TLC), haemoglobin $(\mathrm{Hb})$, packed cell volume $(\mathrm{PCV})$, total protein $(\mathrm{TP})$ and $\mathrm{pH}$. These parameters were evaluated immediately after blood collection and thereafter on day-1, day-3, day-7, day-14, day21 and day- 28 for both the groups.

Results: In both groups, the TEC, TLC, Hb and PCV values were decreased gradually from day-1 onward. In ACD preserved blood, the control values of TEC (11.27 $\pm 0.26 \mathrm{million} / \mathrm{cumm})$, TLC $(8.85 \pm 0.22$ thousand/cumm $), \mathrm{Hb}(8.61 \pm 0.13 \mathrm{~g} / \mathrm{dl})$ and PCV $(30.75 \pm 0.59 \%)$ were decreased to TEC $(9.21 \pm 0.38 \mathrm{million} / \mathrm{cumm})$, TLC $(7.58 \pm 0.10$ thousand/cumm), $\mathrm{Hb}(7.03 \pm 0.06 \mathrm{~g} / \mathrm{dl})$ and PCV $(22.25 \pm 0.53 \%)$ respectively on day-7 which was statistically significant $(p<0.05)$. However, the gradual decrease in the parameters was also noticed from day-7 onward. On the other hand, in case of CPDA-1 preserved blood, the control values of TEC (11.88 $\pm 0.28 \mathrm{million} / \mathrm{cumm})$, TLC (8.91 \pm 0.26 thousand/cumm), $\mathrm{Hb}(8.91 \pm 0.42 \mathrm{~g} / \mathrm{dl})$ and PCV $(32.13 \pm 0.79 \%)$ were found decreasing slightly with the progression of the preservation period, but the changes were statistically significant $(p<0.05)$ on day-21 [TEC $(8.06 \pm 0.22$ million/cumm $), \quad$ TLC $\quad(6.28 \pm 0.34$ thousand/cumm $), \mathrm{Hb}(6.28 \pm 0.16 \mathrm{~g} / \mathrm{dl})$ and PCV $(25.02 \pm 0.46 \%)$ respectively] and onward. Changes in the TP and $\mathrm{pH}$ values were also noticed in both the groups during the experiment but CPDA-1 group showed less alteration than ACD group as compared to the control values.

Conclusion: The results of this study revealed that CPDA-1 can be used for storing caprine blood longer period for transfusion in comparison to $\mathrm{ACD}$ with greater $\mathrm{RBC}$ viability.

Keywords: Haemato-biochemical Parameters, Blood Transfusion, ACD, CPDA-1, Goats 


\section{Introduction}

Blood is an essential body fluid composed of blood cells suspended in blood plasma. Blood transfusion therapy for ruminants is scarce in relation to blood storage. The indications of fresh blood transfusion are life-threatening anaemia, acute traumatic haemorrhage, surgical intervention, parasitism, leukemia, thrombocytopaenia, burns, haemodialysis, etc. (Tocci, 2010). Blood collection and storage systems are licensed by the Food and Drug Administration (FDA) for stored RBC up to 42 days, while the median duration of storage of red cell units in the United States of America is 15 days (Koch et al., 2008). During storage, preserved blood cells undergo progressive structural and functional changes (Yoshida et al., 2019) that may reduce red cell function and viability after transfusion. Blood transfusion restores perfusion of tissues by improving blood oxygen carrying capacity. Several factors are considered before blood transfusion, such as transmission reactions, costs, and difficulties in acquiring proper blood products. Therefore, blood transfusions should be restricted to animals with critical indicators (Kaneko et al., 2008). Platelets circulate longer when stored at room temperature and are more activated and able to form clot more effectively when stored at $4^{\circ} \mathrm{C}$ (Adias et al., 2012). White blood cells lose their phagocytic property within 4 to 6 hours of collection and become non-functional after 24 hours of storage (Thon et al., 2008). It is important to remember that they do not lose their antigenic property and are capable of sensitizing the recipient to produce non-haemolytic febrile transfusion reactions and few lymphocytes may remain viable even after 3 weeks of storage (Batham and Nayak, 2018). Although blood transfusion is being practiced for many years, recently there has been a great attention for its use in farm animals and veterinary medicine (Kumar, 2017). Since goats are considered as farm animals, blood transfusion can be a great life-saving approach during emergency for these animals. In our country large amount of blood is wasted every day in the abattoir. Therefore, the sources of blood are adequate. Now an appropriate technique for collection and preservation of blood needs to be developed so as to institute transfusion therapy at the time of emergency (Alam and Hossain, 2005). Due to the lack of studies related to the use of blood transfusions in goats, and the probable haematological, and biochemical changes are yet to be considered. This study is therefore, conducted to investigate the changes of haematological and biochemical parameters of caprine blood during prolong storage and the efficacy of ACD and CPDA-1 for long term storage of caprine blood for transfusion.

\section{Materials and Methods}

This experiment was carried out from January to November, 2017 in Black Bengal goats to find out the haemato-biochemical changes of caprine blood during storage period at the Department of Surgery and Obstetrics, Bangladesh Agricultural University (BAU), Mymensingh.

\section{Experimental design}

Sixteen (16) apparently healthy goats were selected randomly and divided equally into two groups: Group A and B. Each group consisted of 8 goats. Blood samples were collected from the goats and preserved with Acid Citrate Dextrose (ACD) solution in case of group A and Citrate Phosphate Dextrose Adenine (CPDA-1) solution in case of group B.

\section{Composition of ACD and CPDA-1 solutions}

ACD Solution: Trisodium citrate 13.2g, Citric acid 4.8g, Dextrose 14.7g, Distilled water 1000 ml; CPDA-1 Solution: Sodium citrate dihydrate $2.3 \mathrm{~g}$, Citric acid monohydrate $0.327 \mathrm{~g}$, Dextrose monohydrate $3.19 \mathrm{~g}$, Sodium biphosphate monohydrate $0.222 \mathrm{~g}$, Adenine $0.0275 \mathrm{~g}$, Distilled water $100 \mathrm{ml}$.

\section{Collection and storage of blood samples}

Blood samples were collected from the goats intended to slaughter for meat consumption in the abattoir. Sixteen goats were physically examined for health and selected for collection of blood samples. Fifty $\mathrm{ml}$ of blood was collected from the jugular vein of each animal using $50 \mathrm{ml}$ sterile plastic syringe and needle. After collection, the blood samples were transferred immediately to the Falcon tubes $(15 \mathrm{ml})$ containing ACD (group A) and CPDA-1 (group B) at a concentration of 1 
$\mathrm{ml}$ of preservative (ACD/CPDA-1) for every $7 \mathrm{ml}$ of blood. Then the samples were kept at $4{ }^{\circ} \mathrm{C}$ in refrigerator for 28 days.

\section{Evaluation of blood parameters}

Haematological parameters; total erythrocyte count (TEC), total leucocyte count (TLC), packed cell volume $(\mathrm{PCV})$, haemoglobin $(\mathrm{Hb})$ and biochemical parameters; $\mathrm{pH}$ and total protein (TP) were evaluated immediately after blood collection and thereafter on day-1, day-3, day-7, day-14, day-21 and day-28 for both the groups. Haematological parameters were assessed manually. Total protein (TP) concentration was determined by the Biuret method with spectrometer and $\mathrm{pH}$ was determined by digital $\mathrm{pH}$ meter.

\section{Statistical Analysis}

The data obtained in the present investigation were analyzed with SPSS software using one way ANOVA (Analysis of Variance). $\mathrm{P}<0.01$ and $\mathrm{P}<0.05$ were considered statistically significant.

\section{Results}

The effects of CPDA-1 and ACD on TEC and TLC of caprine blood are presented in Figure-1 and Figure-2 respectively. In case of TEC for CPDA-1 group, the mean control value was $11.88 \pm 0.28 \mathrm{million} / \mathrm{cumm}$, which decreased to $11.65 \pm 0.15,11.38 \pm 0.13,11.35 \pm 0.16,10.66 \pm 0.33$, $8.06 \pm 0.22$ and $7.37 \pm 0.09$ million/cumm on day-1, day-3, day-7, day-14, day-21 and day-28 respectively. Whereas for ACD group, the mean control value was $11.27 \pm 0.26 \mathrm{million} / \mathrm{cumm}$, which decreased to $10.80 \pm 0.21,10.21 \pm 0.30$, $9.21 \pm 0.38,8.29 \pm 0.43,7.41 \pm 0.51$ and $6.76 \pm 0.40$ million/cumm on day-1, day-3, day-7, day-14, day- 21 and day-28 respectively. In case of TLC for CPDA-1 group, the mean control value was $8.91 \pm 0.26$ thousand/cumm, which decreased to $8.85 \pm 0.11, \quad 8.76 \pm 0.22, \quad 8.76 \pm 0.10, \quad 7.86 \pm 0.10$, $6.28 \pm 0.34$ and $4.56 \pm 0.13$ thousand/cumm on day1, day-3, day-7, day-14, day-21 and day-28 respectively. Similarly, for ACD group, the mean control value was $8.85 \pm 0.22$ thousand/cumm, which decreased to $8.80 \pm 0.19, \quad 8.74 \pm 0.18$, $7.58 \pm 0.10,5.76 \pm 0.11,3.99 \pm 0.10$ and $1.80 \pm 0.10$ thousand/cumm on day-1, day-3, day-7, day-14, day-21 and day-28 respectively.

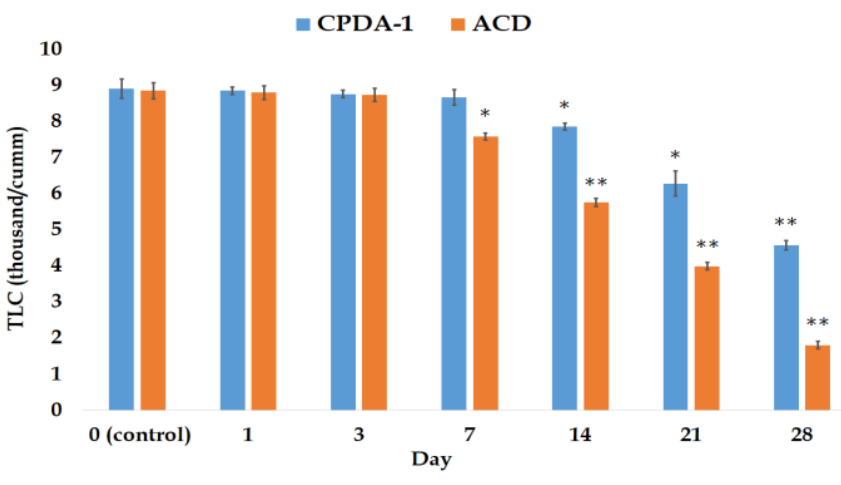

Figure-2: Effects of CPDA-1 and ACD on TLC

$\pm=$ Standard Error, $* *=$ Significant at $1 \%$ level of significance, $*=$ Significant at $5 \%$ level of significance

The effects of CPDA-1 and ACD on $\mathrm{Hb}$ and PCV of caprine blood are presented in Figure-3 and Figure-4 respectively. In case of $\mathrm{Hb}$ for CPDA-1 group, the mean control value was $8.91 \pm 0.42 \mathrm{~g} / \mathrm{dl}$ which decreased to $8.88 \pm 0.18,8.63 \pm 0.16$, $8.00 \pm 0.15,7.23 \pm 0.17,6.28 \pm 0.16$ and $4.96 \pm 0.19$ $\mathrm{g} / \mathrm{dl}$ on day-1, day-3, day-7, day-14, day-21 and day-28 respectively. On the other hand, for ACD group, the mean control value was $8.61 \pm 0.13 \mathrm{~g} / \mathrm{dl}$ which decreased to $8.24 \pm 0.54,7.80 \pm 0.06$, $7.03 \pm 0.06,5.95 \pm 0.18,4.83 \pm 0.21$ and $3.78 \pm 0.19$ $\mathrm{g} / \mathrm{dl}$ on day-1, day-3, day-7, day-14, day-21 and day-28 respectively. In case of PCV for CPDA-1 group, the mean control value was $32.13 \pm 0.79 \%$ 


\section{Jahan and others}

which decreased to $31.13 \pm 1.18,31.06 \pm 0.64$, $30.12 \pm 0.52, \quad 29.07 \pm 0.60, \quad 25.02 \pm 0.46 \quad$ and $16.38 \pm 0.50 \%$ on day- 1 , day-3, day-7, day-14, day-21 and day-28 respectively. On the other hand, for ACD group, the mean control value was
$30.75 \pm 0.59 \%$ which decreased to $28.63 \pm 0.38$, $25.38 \pm 0.32,22.25 \pm 0.53,18.88 \pm 0.64,12.88 \pm 0.71$ and $8.35 \pm 0.88 \%$ on day-1, day-3, day-7, day-14, day-21 and day-28 respectively.

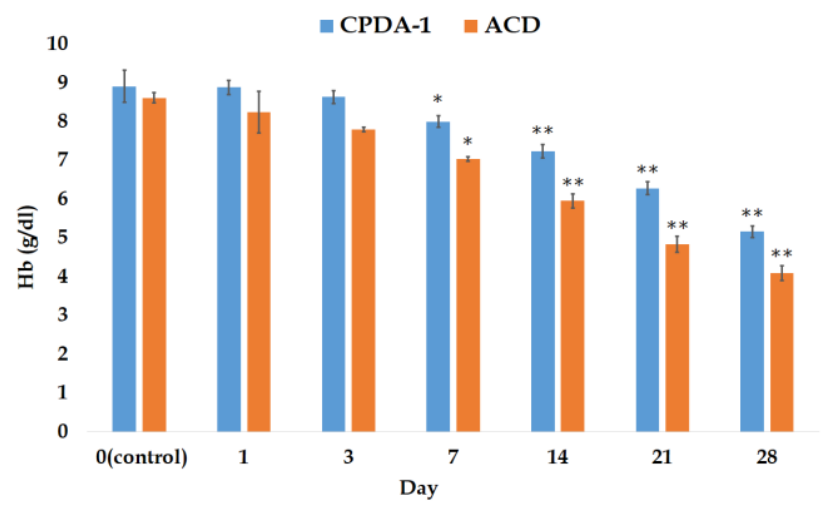

Figure-3: Effects of CPDA-1 and ACD on $\mathrm{Hb}$

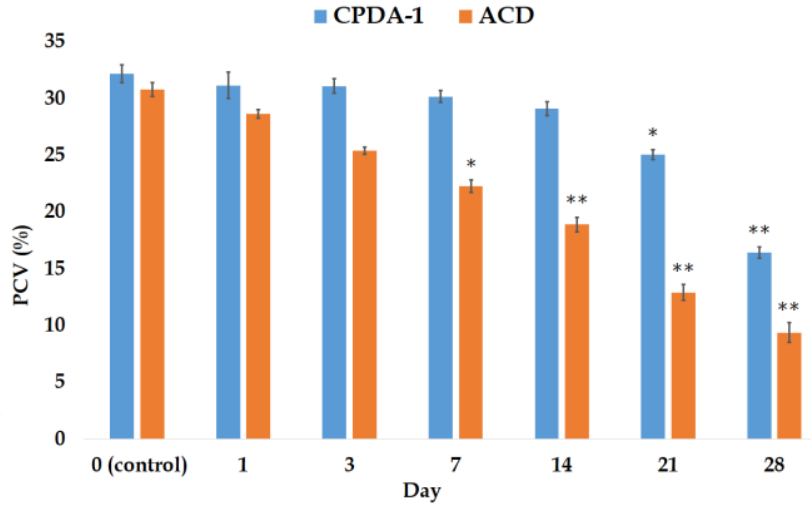

Figure-4: Effects of CPDA-1 and ACD on PCV

$\pm=$ Standard Error, $* *=$ Significant at $1 \%$ level of significance, $*=$ Significant at $5 \%$ level of significance

The effects of CPDA-1 and ACD on TP and $\mathrm{pH}$ of caprine blood are presented in Figure-5 and Figure- 6 respectively. In case of TP for CPDA-1 group, the mean control value was $6.21 \pm 0.01 \mathrm{~g} \%$ which changed to $6.23 \pm 0.01,6.33 \pm 0.01$, $6.28 \pm 0.01,6.15 \pm 0.01,6.10 \pm 0.00$ and $6.03 \pm 0.01$ $\mathrm{g} \%$ on day-1, day-3, day-7, day-14, day-21 and day-28 respectively. For ACD group, the mean control value of TP was $6.20 \pm 0.01 \mathrm{~g} \%$ which changed to $6.25 \pm 0.01,6.32 \pm 0.01,6.20 \pm 0.01$, $6.14 \pm 0.01,6.06 \pm 0.01$ and $5.99 \pm 0.01 \mathrm{~g} \%$ on day- 1 , day-3, day-7, day-14, day-21 and day-28 respectively. In case of $\mathrm{pH}$ for CPDA-1 group, the mean control value was $7.05 \pm 0.01$ which decreased to $7.01 \pm 0.01,6.96 \pm 0.01,6.87 \pm 0.01$, $6.81 \pm 0.01,6.70 \pm 0.01$ and $6.40 \pm 0.03$ on day- 1 , day-3, day-7, day-14, day-21 and day-28 respectively. For ACD group, the mean control value of $\mathrm{pH}$ was $6.92 \pm 0.12$ which decreased to $6.90 \pm 0.01, \quad 6.86 \pm 0.02, \quad 6.76 \pm 0.03, \quad 6.58 \pm 0.02$, $6.50 \pm 0.02$ and $6.42 \pm 0.01$ on day- 1 , day-3, day-7, day-14, day-21 and day-28 respectively.

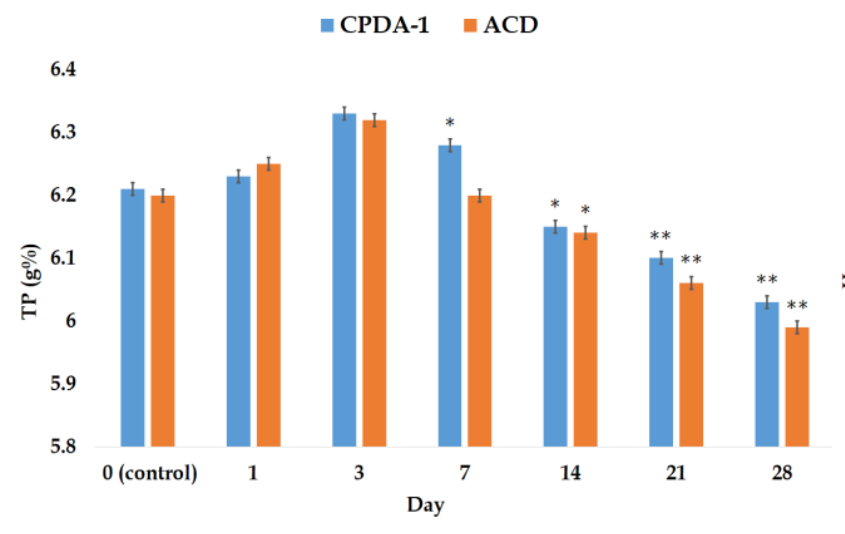

Figure-5: Effects of CPDA-1 and ACD on TP

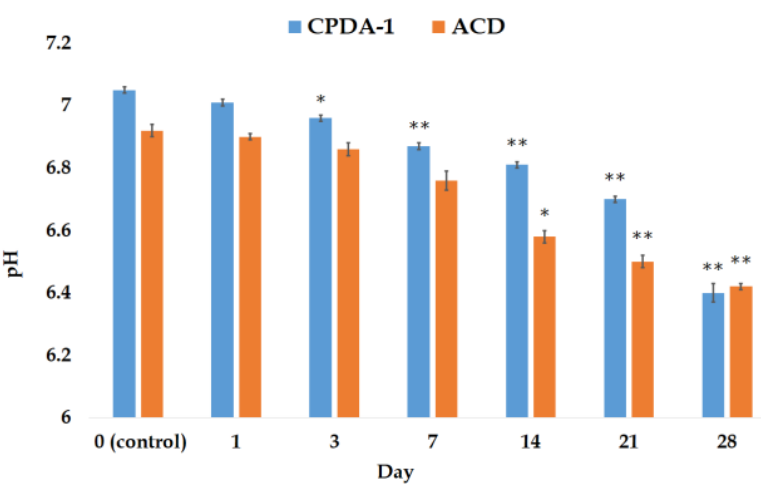

Figure-6: Effects of CPDA-1 and ACD on $\mathrm{pH}$

$\pm=$ Standard Error, $* *=$ Significant at $1 \%$ level of significance, $*=$ Significant at $5 \%$ level of significance 


\section{Discussion}

Keeping quality of caprine blood either with ACD or CPAD-1 was evaluated over a period of 28 days. There was gradual decrease in TEC, TLC, $\mathrm{Hb}, \mathrm{PCV}, \mathrm{TP}$ and $\mathrm{pH}$ values in this experiment as compared to the control values, as also observed by other investigators (Hess, 2006; Ahmed et al., 2009). It appeared that CPDA-1 had better blood preservation capacity than ACD as ACD brought about a significant reduction in TEC, TLC, Hb and PCV values on day-7 and onward while CPDA-1 caused significant reduction in TEC on day-21 and onward, TLC on day-14 and onward, $\mathrm{Hb}$ on day-7 and onward, PCV on day-21 and onward as compared to the control values. The reduction in the values of these parameters may be due to the haemolysis that occurs during storage (Ahmed et al., 2009). The erythrocyte haemolysis can be attributed to several causes including: old erythrocyte age (Emmannel, 2001), progressive structural and functional changes during storage (Koch et al., 2008), improper storage of blood (higher than $8^{\circ} \mathrm{C}$ in blood bank refrigerator) or blood bags leading to decrease in 2,3-diphosphoglycerate (DPG) which is very important to preserve RBC and maintain physiological functions. In addition, during storage leucocytes break down and release their constituents such as hydrogen peroxide and proteases which damage the erythrocytes (Nelson, 1991). The changes in white blood cell counts are most likely due to the changes in the sum effects of the loss of individual cell characteristics specifically degeneration as the cell ages (Elemchukwu et al., 2014). In case of CPDA-1, the presence of adenine improved the synthesis of adenosine triphosphate (ATP) in the stored blood, which prolonged the viability of blood cells at $4{ }^{\circ} \mathrm{C}$ which is similar to the findings of Rejane et al. (2014).

PCV values decreased throughout the experiment in both the groups due to haemolysis of RBC. $\mathrm{Hb}$ values decreased similarly throughout the experiment in both the groups due to denaturation and alteration of $\mathrm{pH}$ during the storage which is in agreements with the findings of Bhomia et al. (2016).
Significant changes in TP value were observed on day-7 and onward as compared to the control in case of CPDA-1 while such changes were observed on day-14 and onward in case of ACD. However, the TP value decreased more in case of ACD than CPDA-1 during the storage. Within day-7, TP values increased in both the cases of CPDA-1 and ACD as compared to the control values. This may be due to the fact that haemoglobin strongly absorbs light at $540 \mathrm{~nm}$ and haemolysis therefore increases absorption in this wavelength range affecting the concentration of different analytes which are measured in this wavelength. The rise in protein concentration is because of optical interference as haemoglobin interferes with protein as it falls in the same absorbance range and intercellular leakage of TP when estimated by biuret method. Similar false elevated level of TP was also observed by Roman et al. (2009). On day-14 and onward, TP values decreased in both the groups as compared to the control values which may be due to the temperature above $0^{\circ} \mathrm{C}$ that denatures the protein by acting on non-covalent (for example, hydrogen, hydrophobic and electrostatic) bonds which are considered important in stabilizing the secondary and tertiary structure (Hashmi et al., 2001).

The $\mathrm{pH}$ values decreased throughout the experiment in both the groups since during the storage there is anaerobic glycolysis and formation of lactic acid and thus falling in $\mathrm{pH}$ values. Similar findings were reported by Verma and Dahiya (2015). Low $\mathrm{pH}$ acts as a factor to reduce the formation of 2,3-DPG (Castilho et al., 2003). ACD solution was found to have lower $\mathrm{pH}$ than that of CPDA-1 solution, therefore 2,3-DPG dropped within the first few days in ACD whereas blood stored in CPDA-1 maintained adequate level of 2,3-DPG up to 14 days.

\section{Conclusion}

CPDA-1 is superior to ACD in case of caprine blood storage at $4^{\circ} \mathrm{C}$ for transfusion.

\section{References}

1. Adias TC, Moore-Igwe B, Jeremiah ZA. Storage related haematological and 
biochemical changes of CPDA-1 whole blood in a resource limited setting. Journal of Blood Disorders and Transfusion. 2012; 3:124.

2. Ahmed Y, Dallal B, Bashar MS. Effect of blood storage on certain haematological parameters. Tikrit Medical Journal. 2009; 15(1):171-180.

3. Alam MR, Hossain MA. Effect of repeated plasma transfusion on various haematological parameters in calves. Pakistan Journal of Biological Sciences. 2005; 8(9):1280-1283.

4. Batham P, Nayak R. Evaluation of haematological parameter in stored CPDA-1 whole blood. International Journal of Applied Research. 2018; 4(11):220-223.

5. Bhomia R, Trivedi V, Coleman NJ, Mitchell JC. The thermal and storage stability of bovine haemoglobin by ultraviolet-visible and circular dichroism spectroscopies. Journal of Pharmaceutical Analysis. 2016; 6(4):242-248.

6. Castilho EM, Glass ML, Manço JC. The effects of 2,3-diphosphoglycerate, adenosine triphosphate, and glycosylated hemoglobin on the hemoglobin-oxygen affinity of diabetic patients. Brazilian Journal of Medical and Biological Research. 2003; 36(6):731-737.

7. Elemchukwu Q, Obeagu EI, Ochei KC. The effect of storage on full blood count in different anticoagulant. IOSR Journal of Dental and Medical Sciences. 2014; 13(9):128-131.

8. Emmannel JC. Clinical use of blood. Blood Transfusion. 2001; 99:265-268.

9. Hashmi M, Tariq S, Nitisewojo P, Rahman R, Mustafa S, Ahmad S. Effect of low temperature storage on protein denaturation in beche-de-mer. Science International. 2001; 13:145-147.

10. Hess JR. An update on solutions for red cell storage. Vox Sanguinis. 2006; 91:13-19.
11. Kaneko JJ, Harvey JW, Bruss ML. Veterinary clinical biochemistry of domestic animals, $6^{\text {th }}$ edition, Academic Press, London. 2008; pp:157-172.

12. Kumar R. Blood transfusion in veterinary medicine. Haematology and Transfusion International Journal. 2017; 4(4):116-122.

13. Koch CG, Li L, Sessler DI, Figueroa P, Hoeltge GA. Duration of red-cell storage and complications after cardiac surgery. New England Journal Medicine. 2008; 23:12291239.

14. Nelson E. Prestorage leucocyte depletion: effect on leucocyte and platelet metabolites, erythrocyte lysis, metabolism and in vitro survival. Seminars in Haematology. 1991; 28(5):3-9.

15. Rejane SS, Antonio H, Hamad M, Carolina A, Sato CA. Survival of transfused homologous erythrocytes in cattle. The Scientific World Journal. 2014; 7:23-24.

16. Roman Y, Bomsel-Demontoy MC, Levrier J, Chaste-Duvernoy D, Jalme MS. Effect of haemolysis on plasma protein levels and plasma electrophoresis in birds. Journal of Wildlife Diseases. 2009; 45:73-80.

17. Thon IN, Schubert P, Duguay M, Serrano K, Lin S. Comprehensive proteomic analysis of protein changing during platelet storage requires complementary proteomic approaches. Transfusion. 2008; 48:425-435.

18. Tocci LJ. Transfusion medicine in small animal practice. Veterinary Clinics of North American Small Animal Practice. 2010; 40 (3):485-494.

19. Verma M, Dahiya K. Effect of blood storage on complete biochemistry. Journal of Blood Disorders and Transfusion. 2015; 6(6):1-4.

20. Yoshida T, Prudent M, D'alessandro A. Red blood cell storage lesion: causes and potential clinical consequences. Blood Transfusion. 2019; 17(1):27-52. 